\title{
Updated high-resolution grids of monthly climatic observations - the CRU TS3.10 Dataset \\ SUPPLEMENTARY INFORMATION
}

\author{
I. Harris, P. D. Jones, T.J. Osborn and D.H. Lister
}

\author{
Climatic Research Unit \\ School of Environmental Sciences \\ University of East Anglia \\ Norwich \\ NR4 7TJ \\ UK
}

\section{Introduction}

This document is a collection of supplementary information for the CRU TS3.10 paper. It contains:

- Web links to sources of data and information

- Detailed information about the updating of databases for each variable

- A brief analysis of the effect of using a wind climatology, rather than monthly observations, in the calculation of PET.

- Supporting plots for the detailed trend analysis carried out with CRUTEM4 (for TMP) and GPCCv5 (for PRE).

\section{Web Links}

Organised by section.

\section{Section 2.1}

MCDW bulletins:

http://www1.ncdc.noaa.gov/pub/data/mcdw/ (eg, 'ssm0812.fin')

CLIMAT reports:

http://hadobs.metoffice.com/crutem3/data/station_updates/

Enquiries for the WWR CD-ROM can be made to wcdmp@wmo.int (according to http://www.wmo.int/pages/prog/wcp/wcdmp/wwr/index en.html). However, it is intended that the CD material will be available online from the WDCA website after some corrections have been made (personal communication by email, Christina Lief, NOAA; 11/05/10].

\section{Section 2.2}

Information document for BoM temperature series:

ftp://ftp.bom.gov.au/anon/home/ncc/www/change/HQdailyT/HQdailyT_info.pdf) 
New Zealand temperature series:

http://www.niwa.co.nz/our-science/climate/news/all/nz-temp-record

Canadian homogenized series:

http://ec.gc.ca/dccha-ahccd/Default.asp?lang=En\&n=B1F8423A-1

Real-time Canadian climate data:

http://climate.weatheroffice.gc.ca/climateData/canada e.html

Section 2.3

Climate data for Iran: http://www.irimet.net/irimo/synoptic1.htm

Wet days database improvement:

Daily Precipitation stations: http://dss.ucar.edu/datasets/ds512.0/

Monthly Precipitation and RDY: http://dss.ucar.edu/datasets/ds570.0/

Section 2.4

Section 2.4.1

MCDW bulletins: http://www1.ncdc.noaa.gov/pub/data/mcdw/ (eg, 'ssm0812.fin')

Section 2.4.2

CLIMAT reports: http://hadobs.metoffice.com/crutem3/data/station_updates/

Section 2.4.3

BOM climate data: http://www.bom.gov.au/climate/data/

\section{Section 3}

NCAR Terrainbase elevation dataset: http://rda.ucar.edu/datasets/ds759.2/

Section 3.3

IDL: http://www.ittvis.com/ProductServices/IDL.aspx

Section 4.1

UDEL Temperature Data:

http://climate.geog.udel.edu/ climate/html_pages/README.ghen_ts2.html

GPCC Precipitation Data: http://gpcc.dwd.de

\section{Section 4.3.1}

CRUTEM3 and CRUTEM4 Data: http://www.cru.uea.ac.uk/cru/data/temperature/ 


\section{Detailed Information: Considerations for Updating Specific Variables}

Mean temperature (TMP):

The CRU monthly global TMP database (Jones and Moberg, 2003) holds more than 5,000 station series. These are routinely updated through the use of CLIMAT and MCDW, and with WWR when those decadal publications become available. For the current study, the most recent (1991-2000) WWR decade became available from NCDC in 2004. Whilst the monthly CLIMAT and MCDW should update most current WMO reporting series in the archive, this is not met in practice. WWR data series offer the potential to infill missing values and highlight possible quality-control (QC) problems in the existing real-time CLIMAT/MCDW-updated series.

The merger of the WWR 1991-2000 series with the existing TMP archive did infill some missing values. The percentage of missing values in the CRU dataset was reduced from $38 \%$ to $34 \%$ during the period 1991-2000. In addition, a comparison between our existing TMP database and the WWR data identified a number of potential quality-control problems in either or both datasets. These shortcomings were identified and, where possible, rectified in our TMP database.

Mean-monthly maximum and minimum temperature (TMX/TMN):

The CRU TMX and TMN archives (updated from New et al., 1999, 2000, by MJ05) were the basis for the extended/updated TMX and TMN archives. Before the current study, these archives held about 7300 series. The main sources of new data were:

- NOAA/NCDC (archives provided by Russell Vose, NCDC)

- CLIMAT - CLIMAT messages have included TMN and TMX data since November 1994

- Canadian archive of homogenized series (Vincent, 1998 and Vincent and Gullet, 1999)

- Australian TMX and TMN archive for the period 2000-2008 (David Jones, BoM, pers. comm. 1 Feb 2006)

The NOAA/NCDC archives do not identify all stations with WMO Station Identifiers as generally used elsewhere in the CRU archives. A matching exercise was undertaken using latitudes, longitudes, station names and elevation. However, such an automated approach, which does not include the matching of overlapping data values, cannot place all series into "known" or "unknown" categories. Of the approximately 10600 station TMX/TMN series 
received, about 3200 remained unidentified. These series may or may not be new to the archive but they have been retained for the later gridding operation but have a lower priority (the priority system for data use in gridding is discussed in Section 3).

The result of the merger between the MJ05 database and the NOAA/NCDC database was then merged with the other three source files listed above. After the final merger operation, the TMX and TMN archives each held over 14000 series (including series without WMO Station Identifiers).

\section{Monthly-total precipitation (PRE)}

Before the current study, the CRU Precipitation archive (updated from Hulme, 1994, by MJ05) held around 12400 station series. This was, and is, updated periodically from CLIMAT and MCDW sources. In addition, contacts and collaborations (as above, for temperature) provided new series and updates to existing series. The principal additional sources used for precipitation were:

- A significant collection of monthly precipitation series - supplied by NCDC.

- WWR 1991-2000

- CD-ROM from the Association of Southeast Asian Nations (ASEAN): The ASEAN Compendium of Climate Statistics.

- Climate data for Iran - a link to this data is given in Section 1 of the Supplementary Information.

Many of the NCDC data series were not identified by WMO Station Identifiers (in a similar manner to that described above for TMX/TMN). Thus a matching exercise was necessary, which matched only 2260 out of the approximately 3800 station series received. As with the TMX and TMN series, the remaining 1540 series may or may not be new to the archive, and they have been retained for the gridding operation but given a lower priority.

The result of the merger between the CRU archive and the NCDC series was then merged with all of the other (source) inputs. As with the TMP/TMX/TMN mergers, comparison of overlapping values from the different sources led to the discovery of individual erroneous values, and appropriate alterations were made. At the end of all merger operations, the precipitation archive held just under 15000 series. 
Monthly counts of rain-days (WET, threshold $\approx 0.1 \mathrm{~mm}$ )

In the following explanation, 'RD0' is used to refer to monthly wet day counts with a threshold of usually $\geq 0.1 \mathrm{~mm}$ but sometimes up to $\geq 0.4 \mathrm{~mm}$ (depending on the reporting station), and 'RDY' refers to monthly rain day counts with a threshold of $\geq 1 \mathrm{~mm}$. The CRU TS 'WET' variable is the monthly count of wet days with $\geq 0.1 \mathrm{~mm}$.

The existing WET database ran to 1989 and had limited coverage, especially before 1970 . Since incoming data from MCDW and CLIMAT are 'RDY' observations, conversion factors from RDY to RD0 were derived as follows. Daily station precipitation measurements were obtained from UCAR (dataset ds512.0), and were processed to produce matched sets of RD0 and RDY counts. Only whole months of daily data were used, leading to temporallyintermittent coverage. Average monthly conversion factors (from RDY to RD0) were then derived as the ratio of RD0/RDY, and averaged into $5^{\circ}$ latitude bands. Coverage at high latitudes was poor, and values from adjacent bands were repeated if there were zero or only a single station in latitude band. The station mean and latitude band mean factors for January and July are shown in Figure S1. Monthly PRE and RDY were also obtained from UCAR (dataset ds570.0). The RDY station data were converted to RD0 using the above factors, and station normals for RD0 produced. The PRE station data, where matching stations were found in the RD0 normals, were then converted to RD0 using equations (4) and (5) (with $x=0.45$ ) from New et al (2000). The resulting RD0 station database, covering the period 1961-2004, was then merged with the existing WET database to form a 'final' database. The RDY-toRD0 banded conversion factors are also used in processing RDY from MCDW and CLIMAT bulletins. 

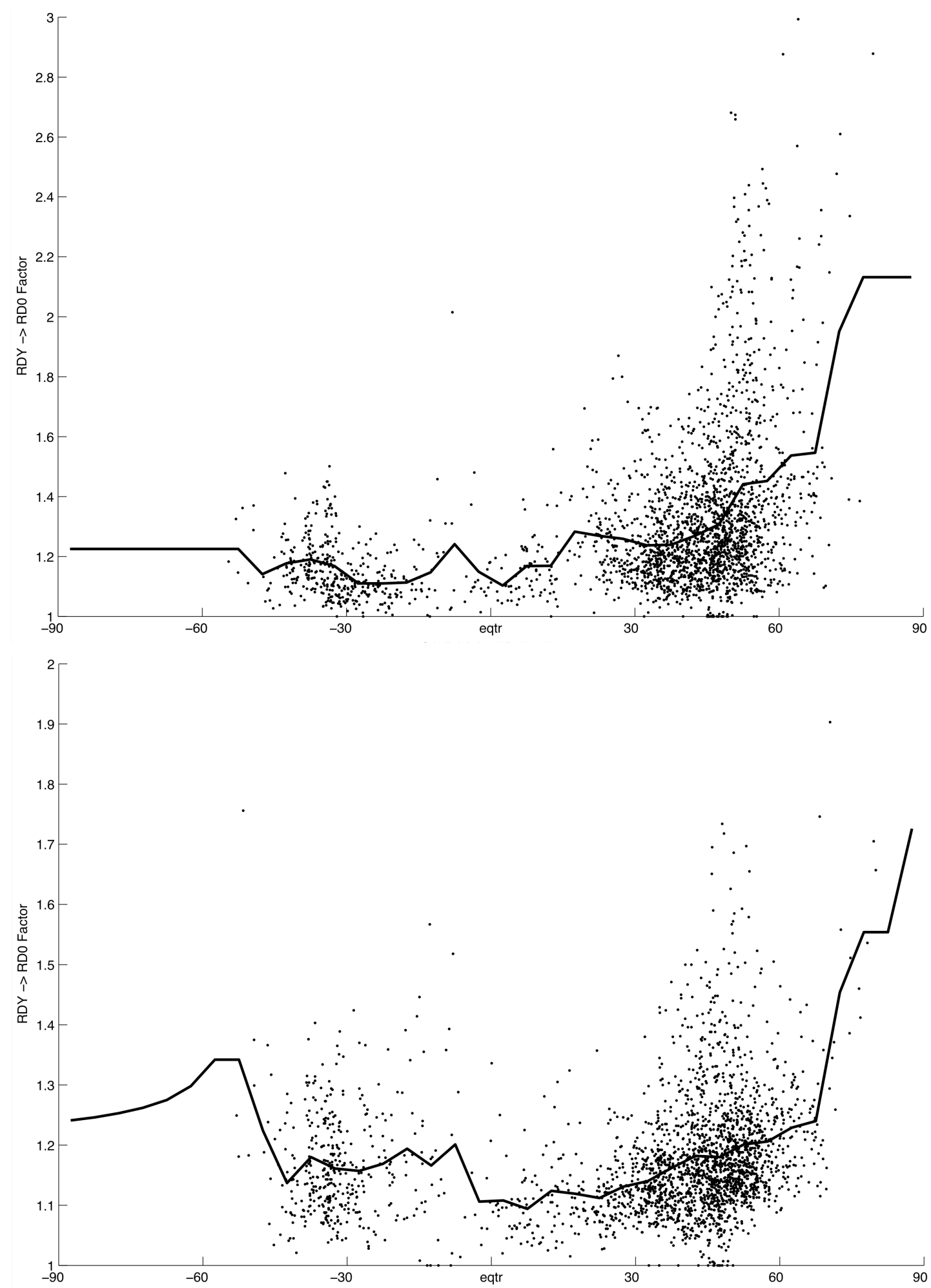

Figure S1. Mean station RDY to RD0 factors by latitude of individual stations (scatter) and $5^{\circ}$-banded means (solid line) for January (top) and July (bottom). 
Mean monthly vapour pressure (VAP) and monthly total of sun-hours (SUNH)

Existing CRU archives (updated from New et al., 2000, by MJ05) have been updated for vapour pressure and sunshine hours (SUNH) using extracts from CLIMAT and MCDW monthly publications. The two source-file series were merged to provide update series for the period 2000-09. SUNH is used as a surrogate for cloudiness from 2003 onwards (see Appendix 3 of the main paper).

\section{Use of a Wind Climatology in Calculating PET}

Because of the insufficient number of monthly wind observations available, the calculation of PET is made using a 1961-1990 wind speed climatology. The question of how this might affect the resulting PET values is investigated here.

Six series of monthly observations of wind speed were chosen for their length and spatial diversity:

\begin{tabular}{|l|l|r|r|r|r|r|}
\hline Country & Name & Lat & Lon & Alt & Start & End \\
\hline UK & Aldergrove & 54.65 & -6.22 & 68 & 1949 & 1995 \\
\hline Canada & Calgary Int'l Airport & 51.12 & -114.02 & 1077 & 1930 & 1991 \\
\hline Bolivia & Trinidad (Aasana) & -14.85 & -64.95 & 157 & 1943 & 1993 \\
\hline S. Africa & Johannesburg & -26.13 & 28.23 & 1694 & 1961 & 1990 \\
\hline China & Shanghai & 31.16 & 121.43 & 4 & 1875 & 1988 \\
\hline Indonesia & Jaya/Sukanapurasent & -2.57 & 140.48 & 98 & 1961 & 1980 \\
\hline
\end{tabular}

The PET process was then run for whatever temporal coverage was offered by the stations between the CRU TS3.10 limits of 1901-2010, for the six half-degree cells occupied by these stations. The other variables were identical to those used in CRU TS3.10. The six PET series resulting from this exercise were then compared to the published v3.10 PET series for the same cells. The comparisons, along with inset comparisons between the published wind climatology and that calculated from the station observations, are shown in figures S2 and S3. There is good agreement in all areas, though increased variability is evident in Bolivia, South Africa and Indonesia.

Since the availability of wind speed observations is too sparse to allow their gridding, and use in the PET calculation, this exercise is for information only. 

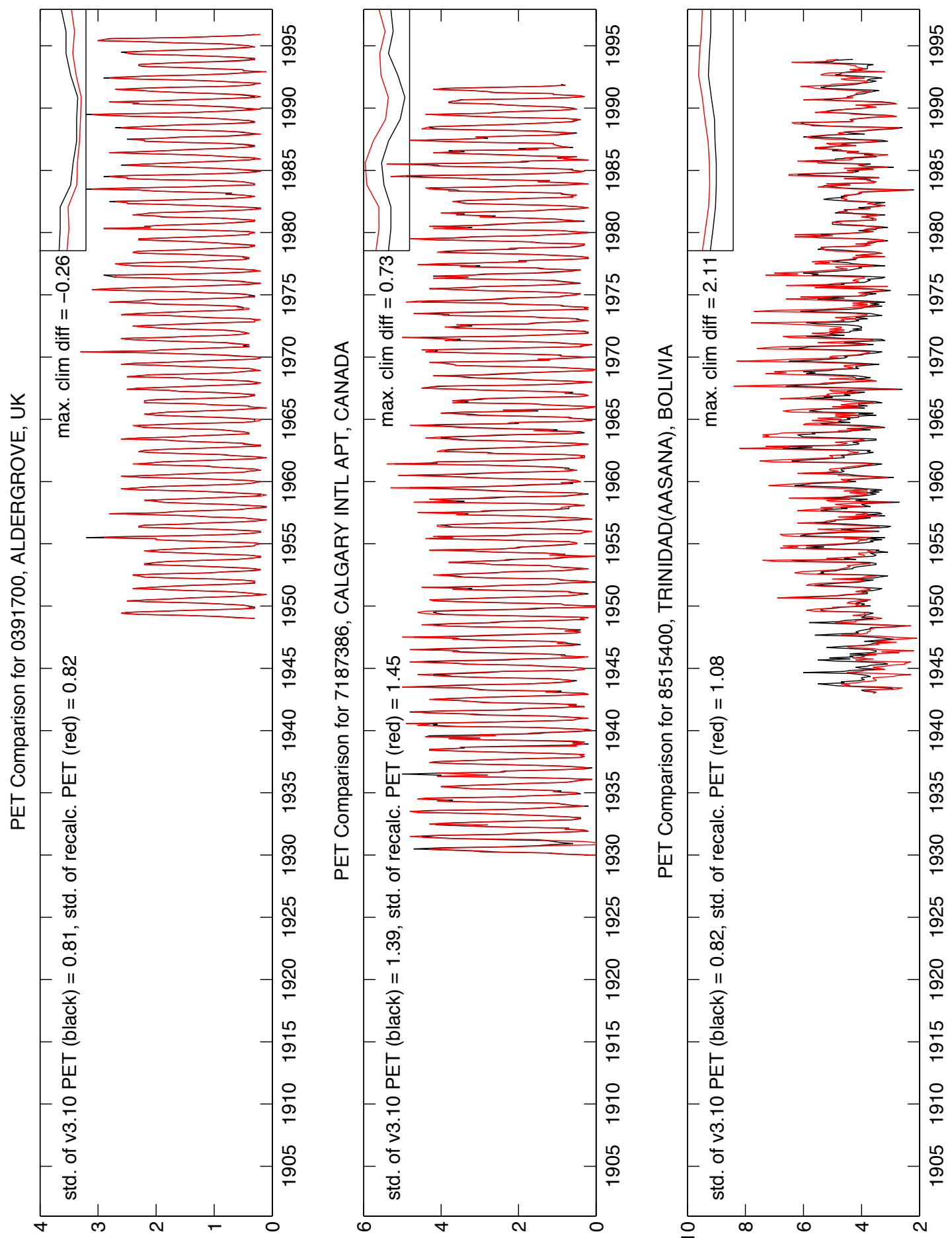

Figure S2. Comparisons (UK, Canada, Bolivia) between CRU TS3.10 PET using the wind climatology (black) and regenerated PET using v3.10 variables and selected wind station observations (red), giving standard deviation figures for both series. Inset: Jan-Dec wind climatology (m/s) as used in CRU TS3.10 (black), and the 1961-1990 monthly mean for the station in question (red), also giving the maximum difference. 

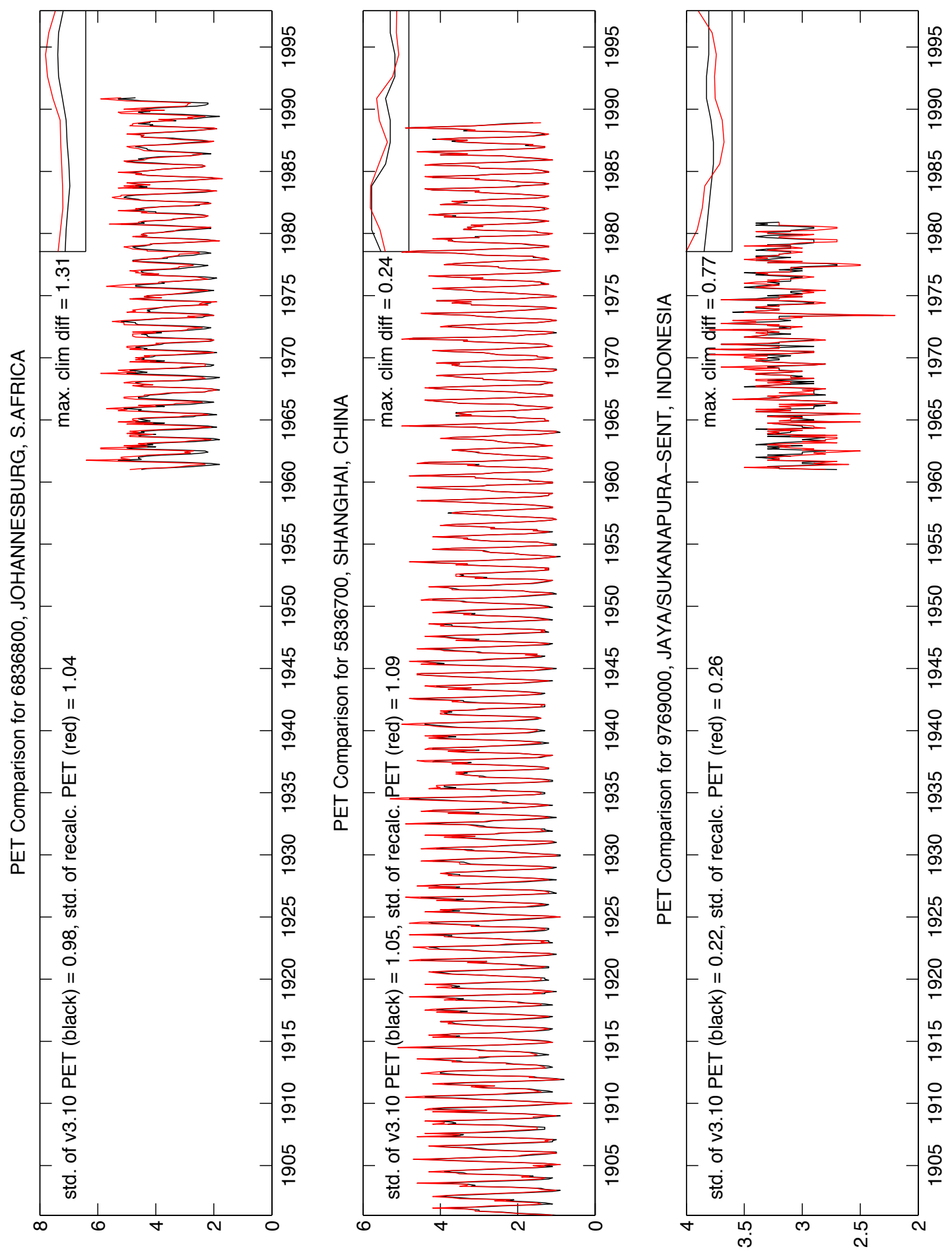

Figure S3. Comparisons (S. Africa, China, Indonesia) between CRU TS3.10 PET using the wind climatology (black) and regenerated PET using v3.10 variables and selected wind station observations (red), giving standard deviation figures for both series. Inset: Jan-Dec wind climatology (m/s) as used in CRU TS3.10 (black), and the 1961-1990 monthly mean for the station in question (red), also giving the maximum difference. 


\section{Trend Analysis and Comparisons}

Trend comparisons were made for TMP (with CRUTEM4) and PRE (with GPCCv5). All datasets were upscaled to a $5^{\circ} \times 5^{\circ}$ spatial resolution, and yearly means (totals for PRE) were calculated. Three time periods were tested: 1901 to 1950,1951 to 2009, and 1901 to 2009.

Trends were compared by calculating 95\% confidence limits, adjusted for autocorrelation. If the CRU TS and CRUTEM4 or GPCCv5 trend gradients overlapped (taking the confidence limits into account), then the two trends were considered to be significantly related rather than independent.

Figures S4 to S9 are pairs of plots for TMP for the three time periods, and figures S10 to S15 show the PRE results. In each pair, the first plot shows the trends and trend differences; the second plot shows the trend consistency tests. 

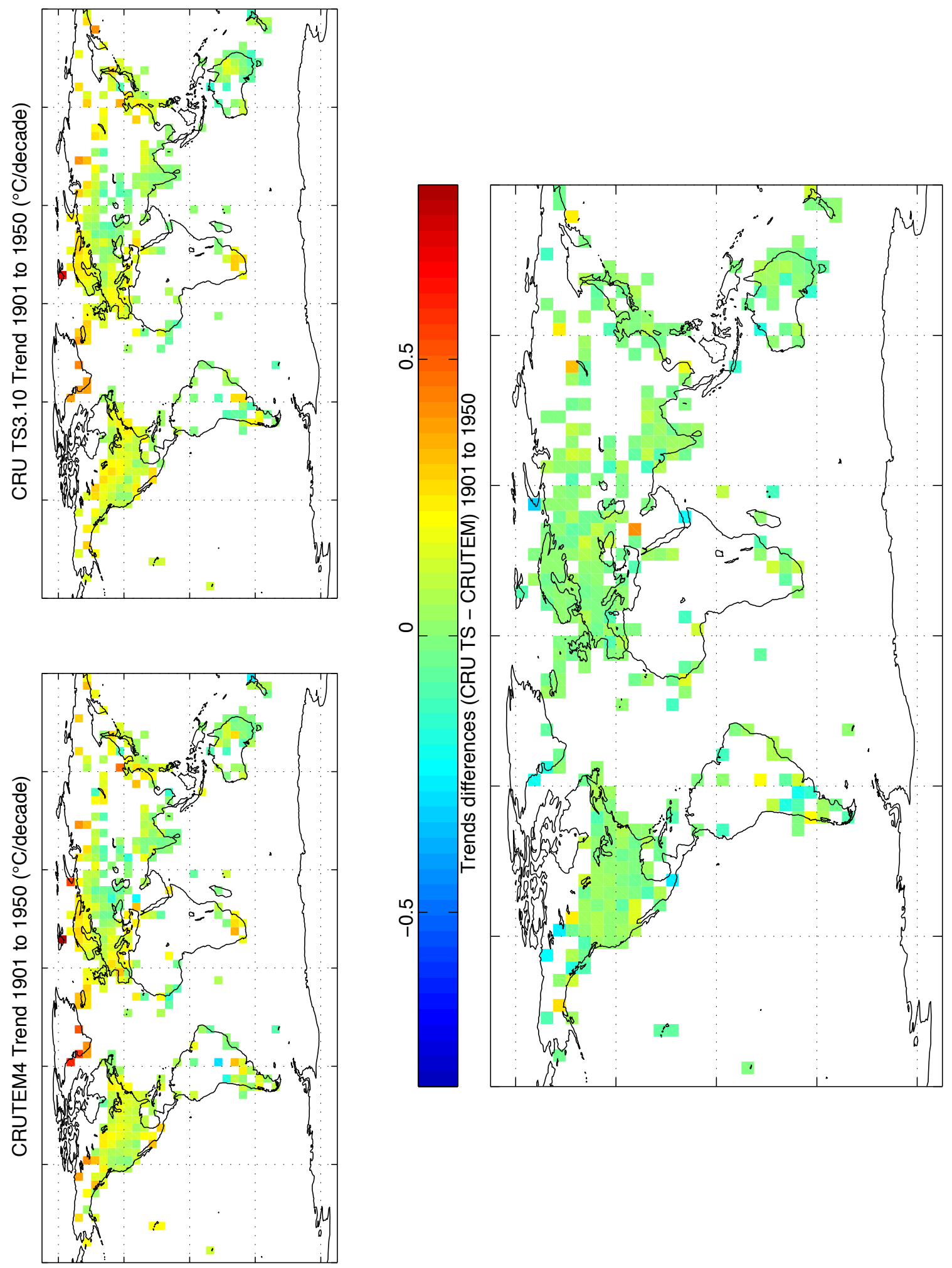

Figure S4. CRUTS and CRUTEM4 trends, and their differences, for 1901 to 1950. 
Test for closeness of trends (1901 to 1950), Independents (95\%) Shown

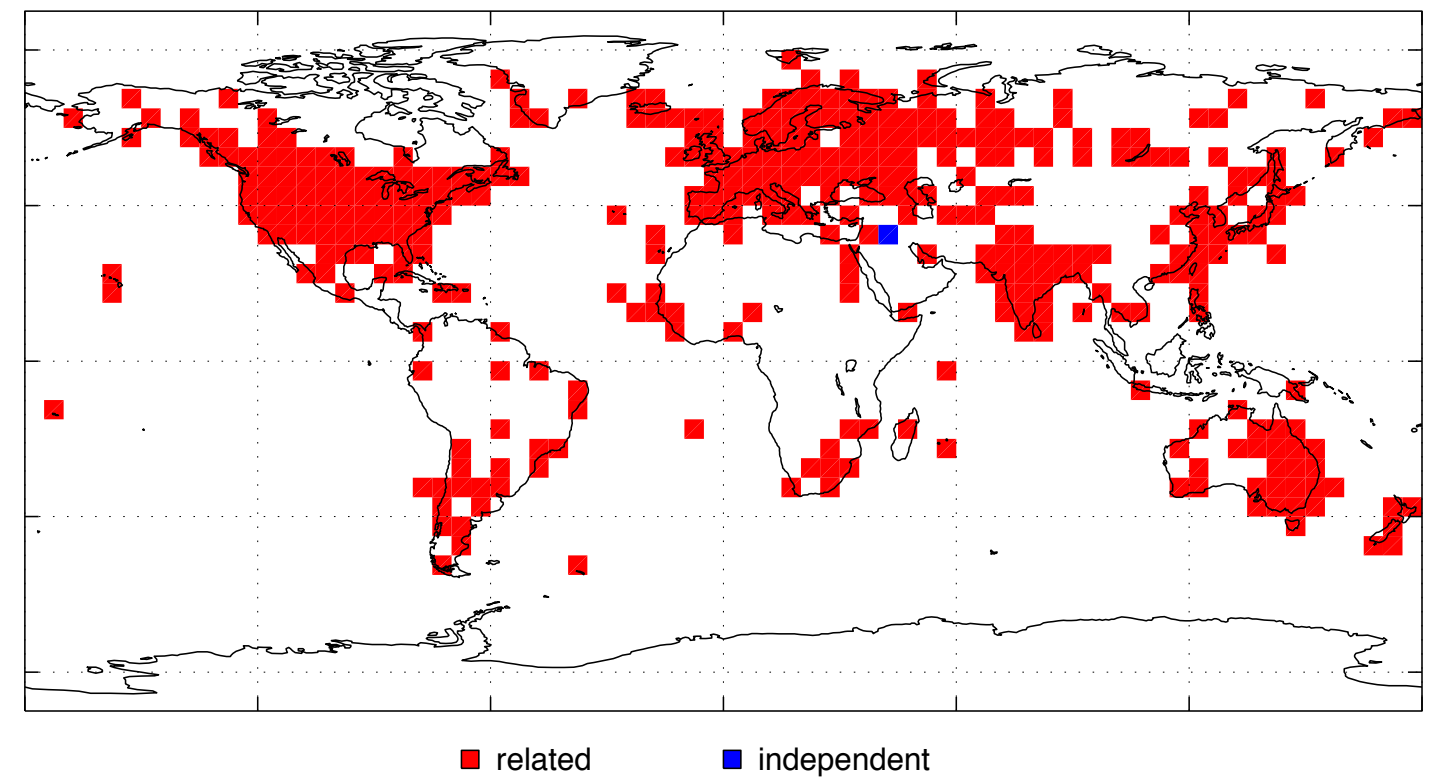

Figure S5. Locations where the CRUTS and CRUTEM4 trends are consistent or are significantly different, for 1901 to 1950 . 

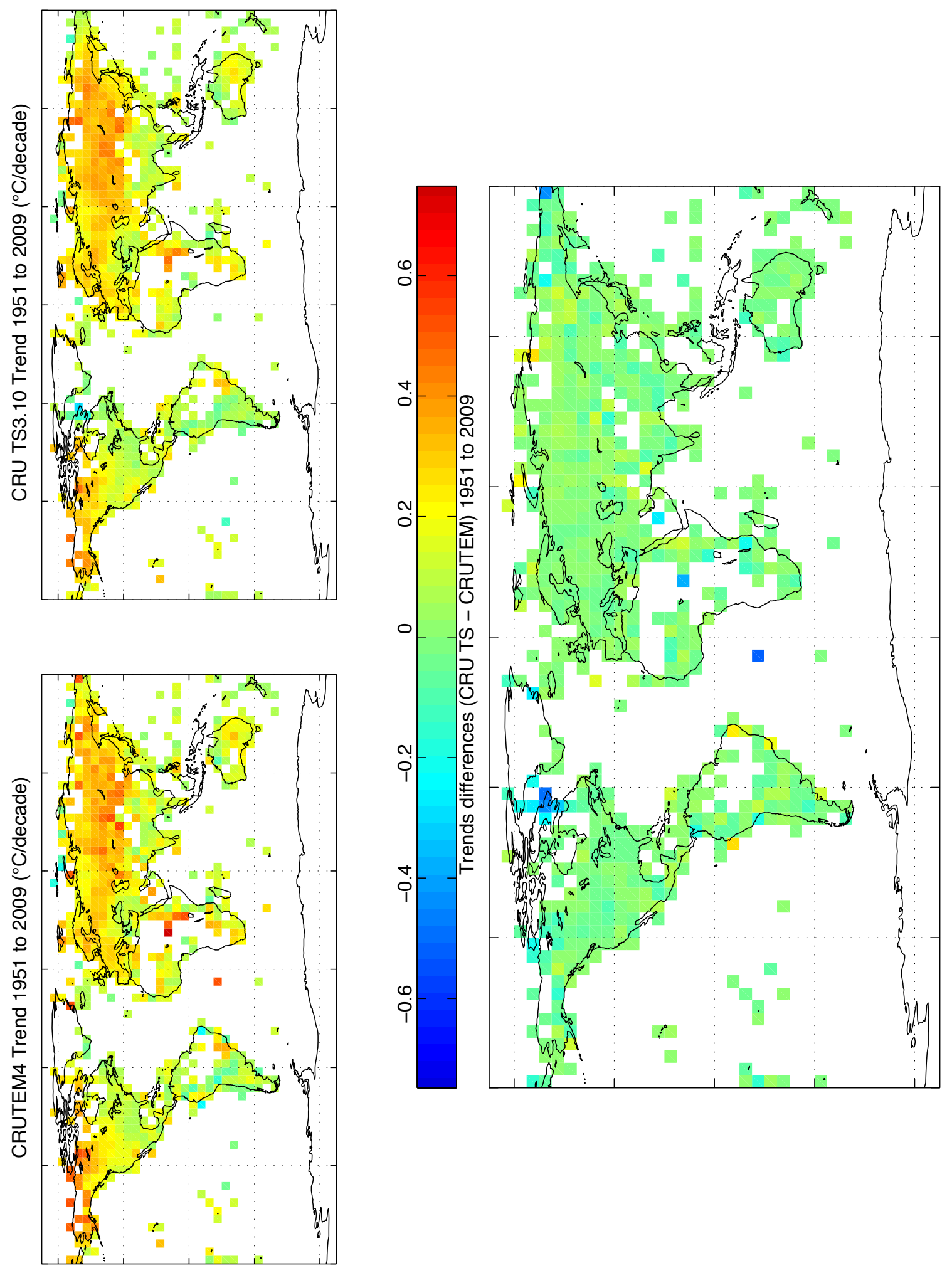

Figure S6. CRUTS and CRUTEM4 trends, and their differences, for 1951 to 2009. 
Test for closeness of trends (1951 to 2009), Independents (95\%) Shown

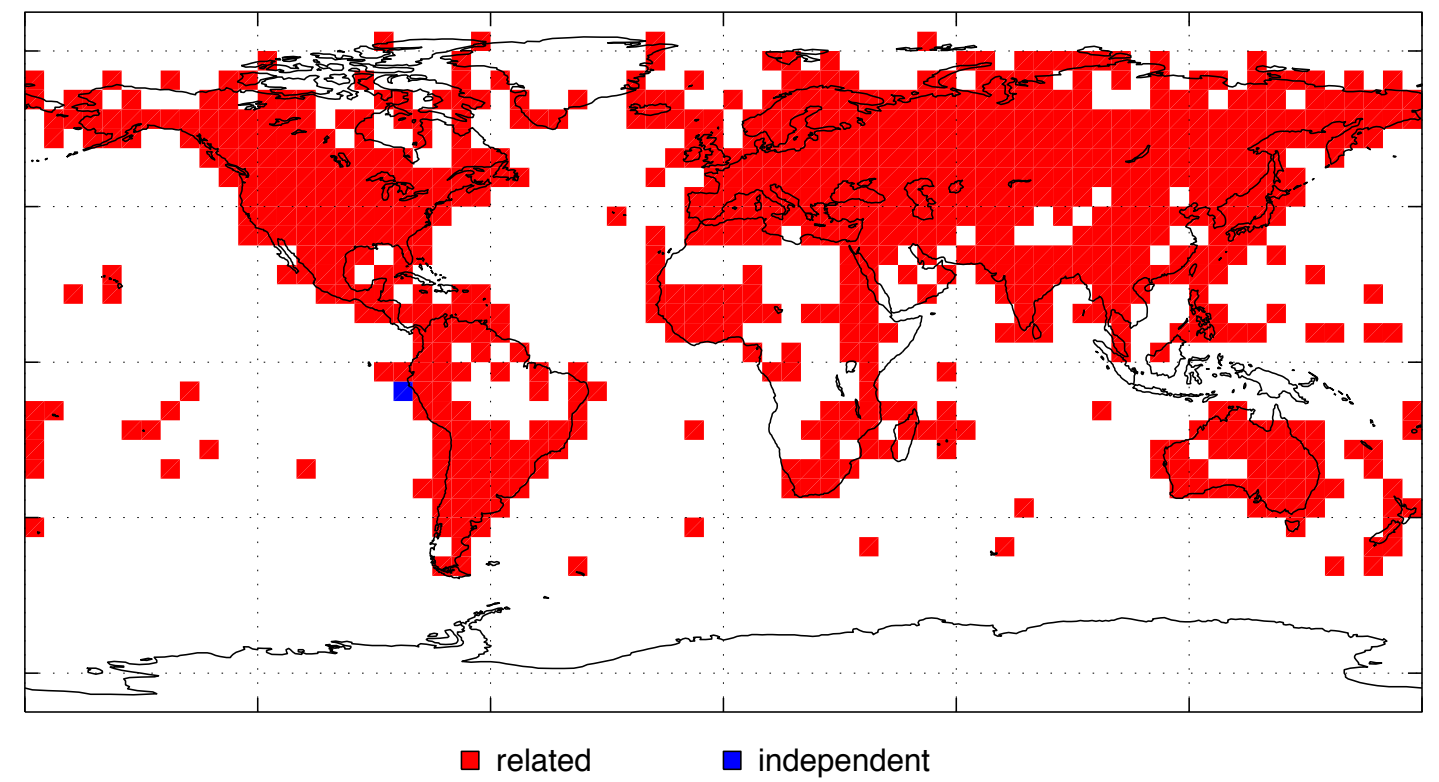

Figure S7. Locations where the CRUTS and CRUTEM4 trends are consistent or are significantly different, for 1951 to 2009. 

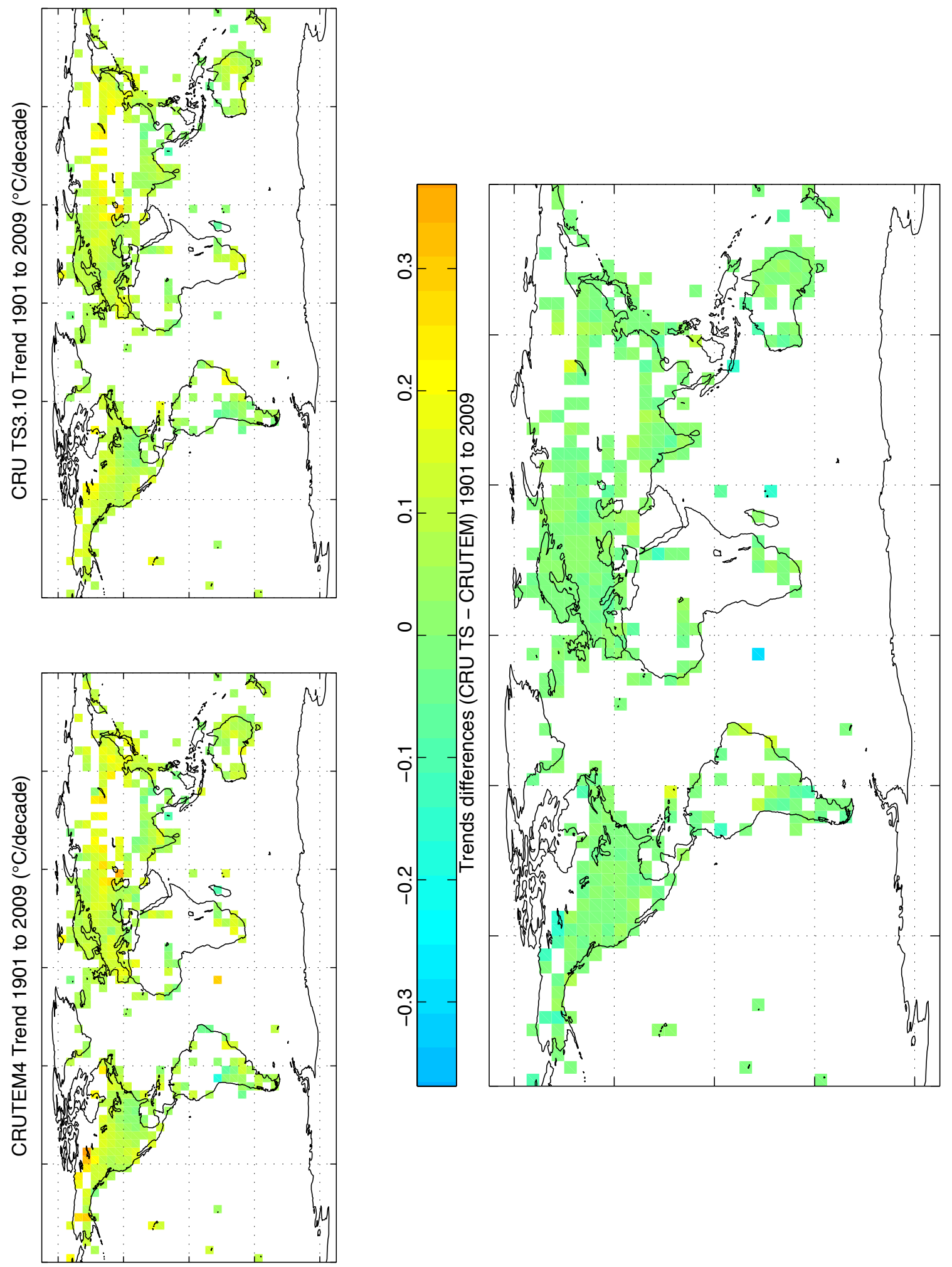

Figure S8. CRUTS and CRUTEM4 trends, and their differences, for 1901 to 2009. 
Test for closeness of trends (1901 to 2009), Independents (95\%) Shown

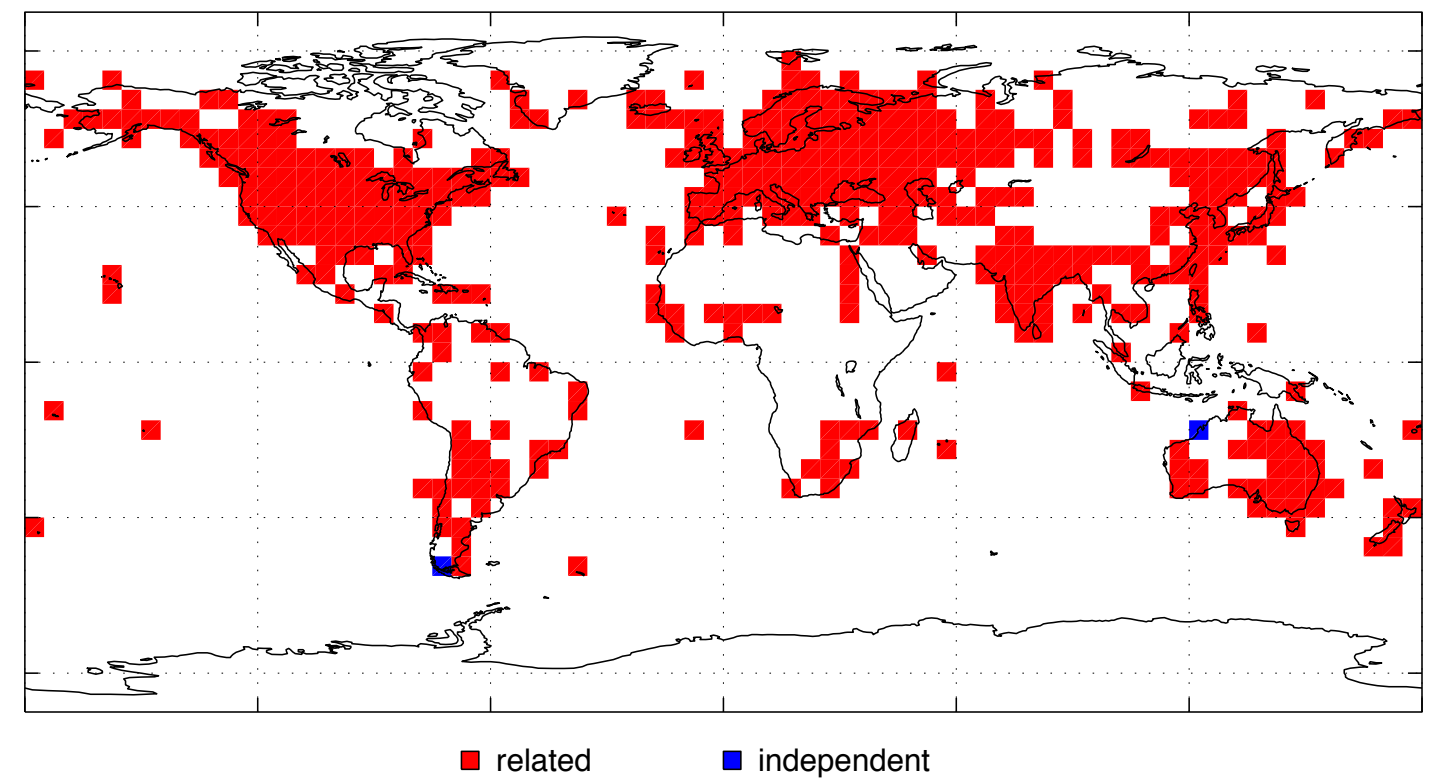

Figure S9 Locations where the CRUTS and CRUTEM4 trends are consistent or are significantly different, for 1901 to 2009. 

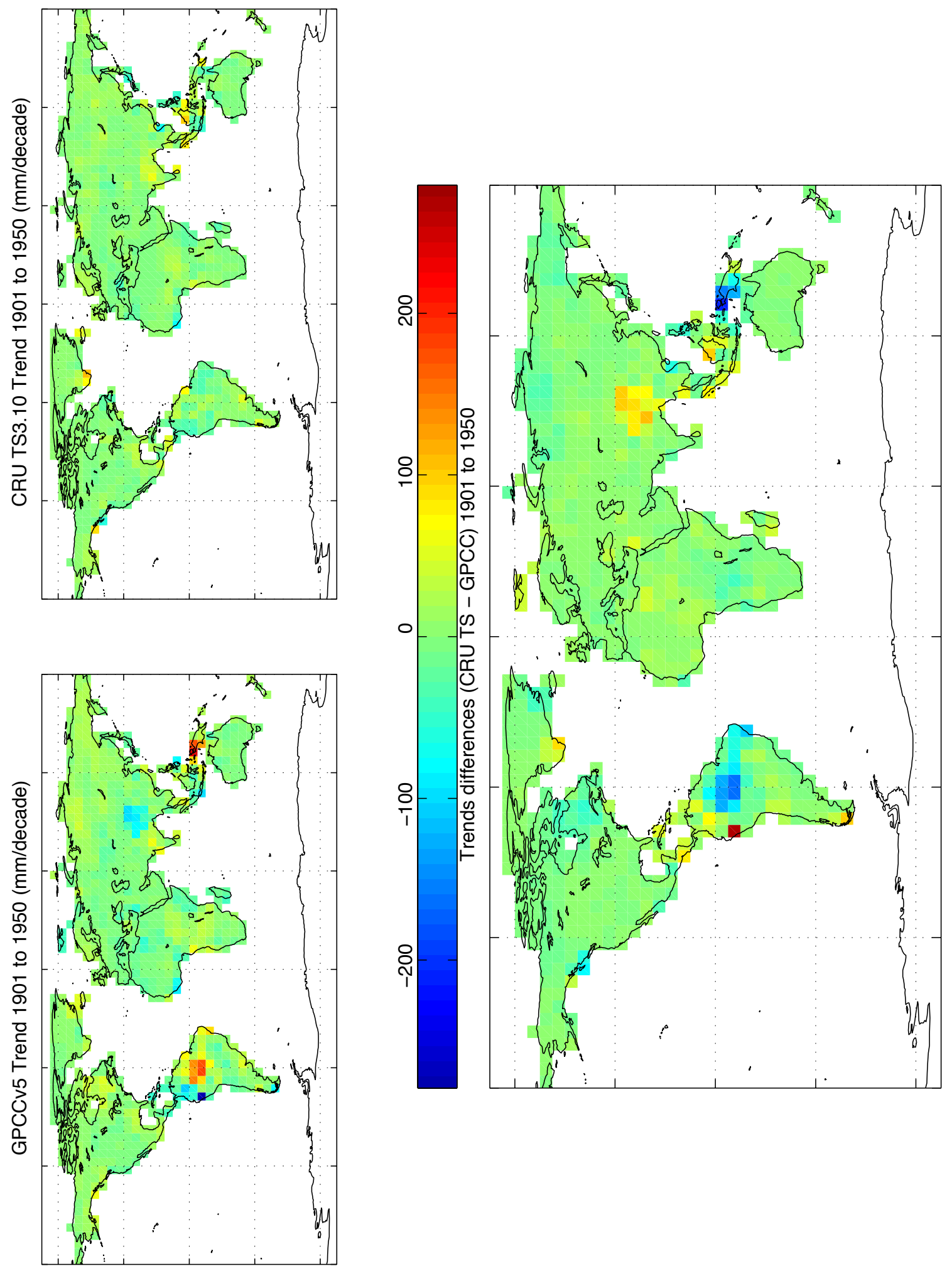

Figure S10. CRUTS and GPCCv5 trends, and their differences, for 1901 to 1950. 


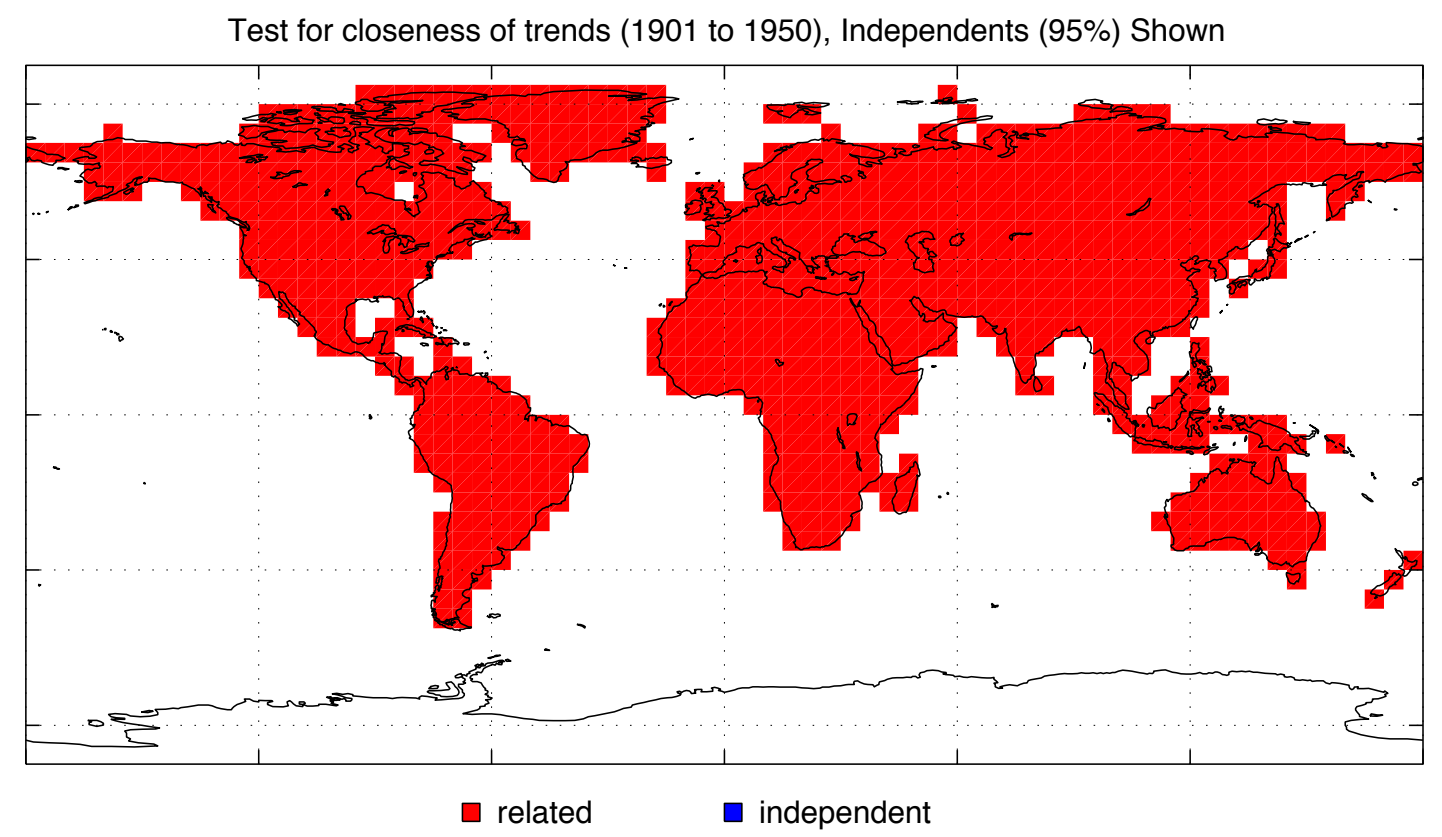

Figure S11. Locations where the CRUTS and GPCCv5 trends are consistent or are significantly different, for 1901 to 1950 . 

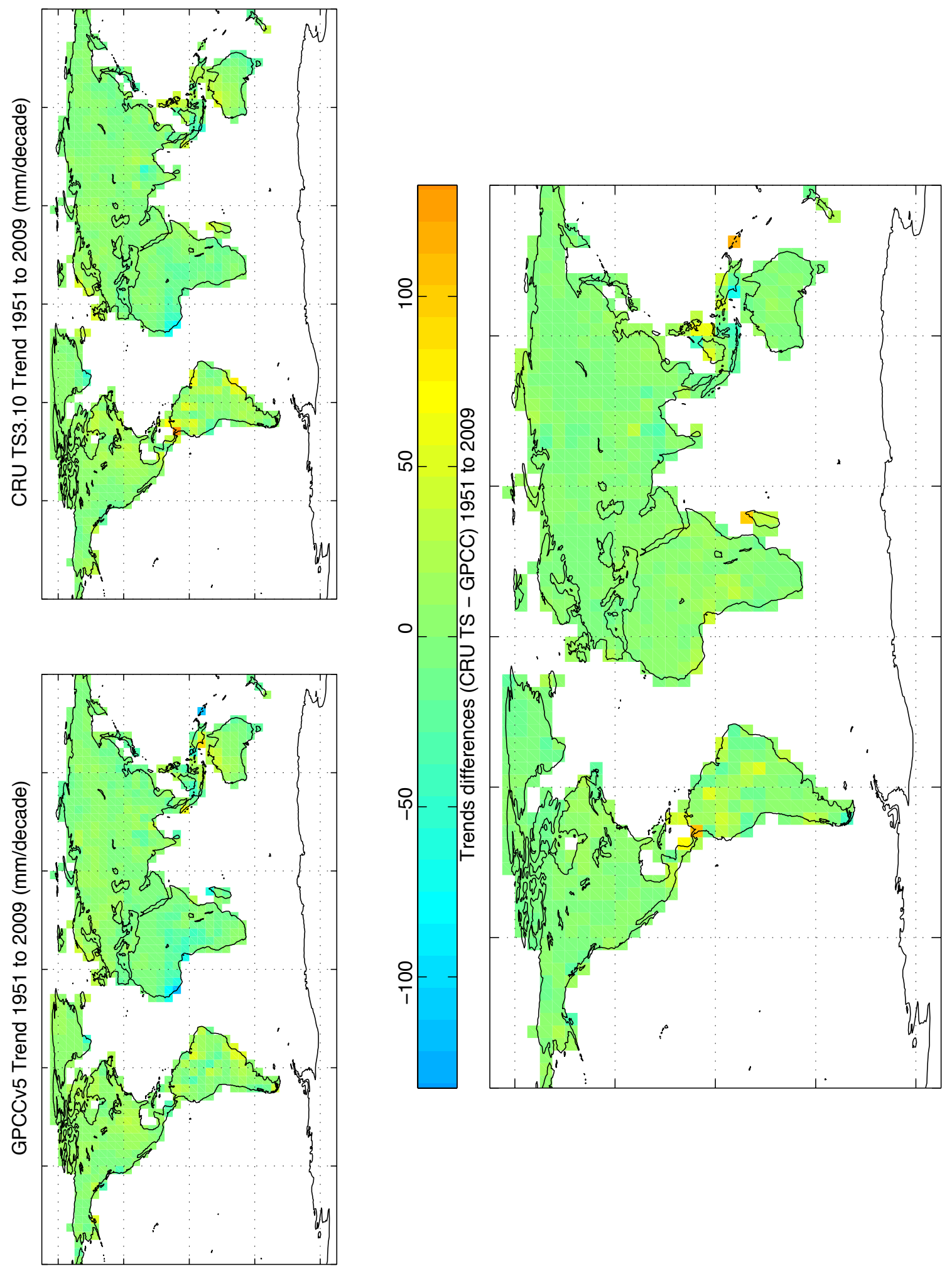

Figure S12. CRUTS and GPCCv5 trends, and their differences, for 1951 to 2009. 


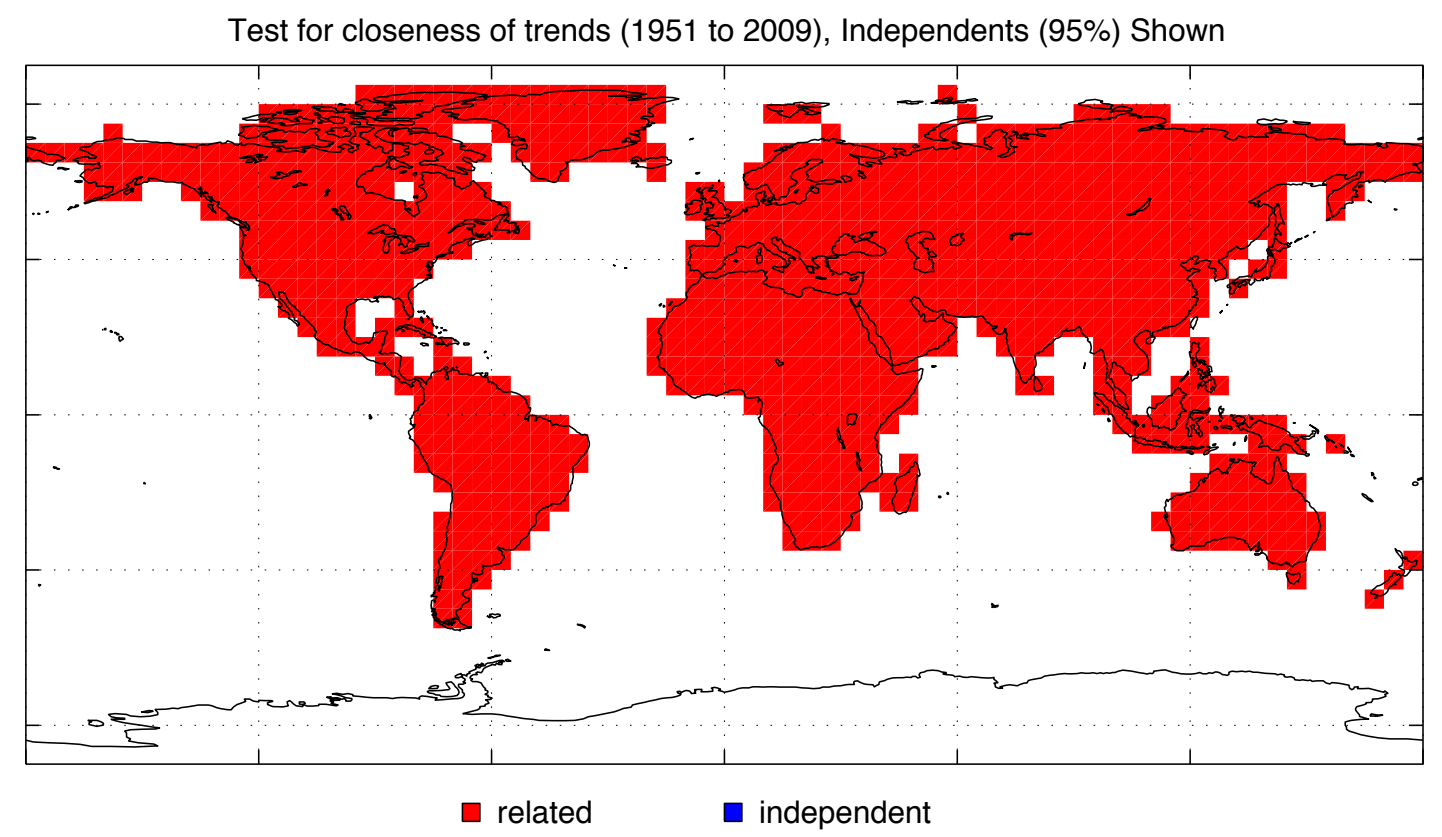

Figure S13. Locations where the CRUTS and GPCCv5 trends are consistent or are significantly different, for 1951 to 2009. 

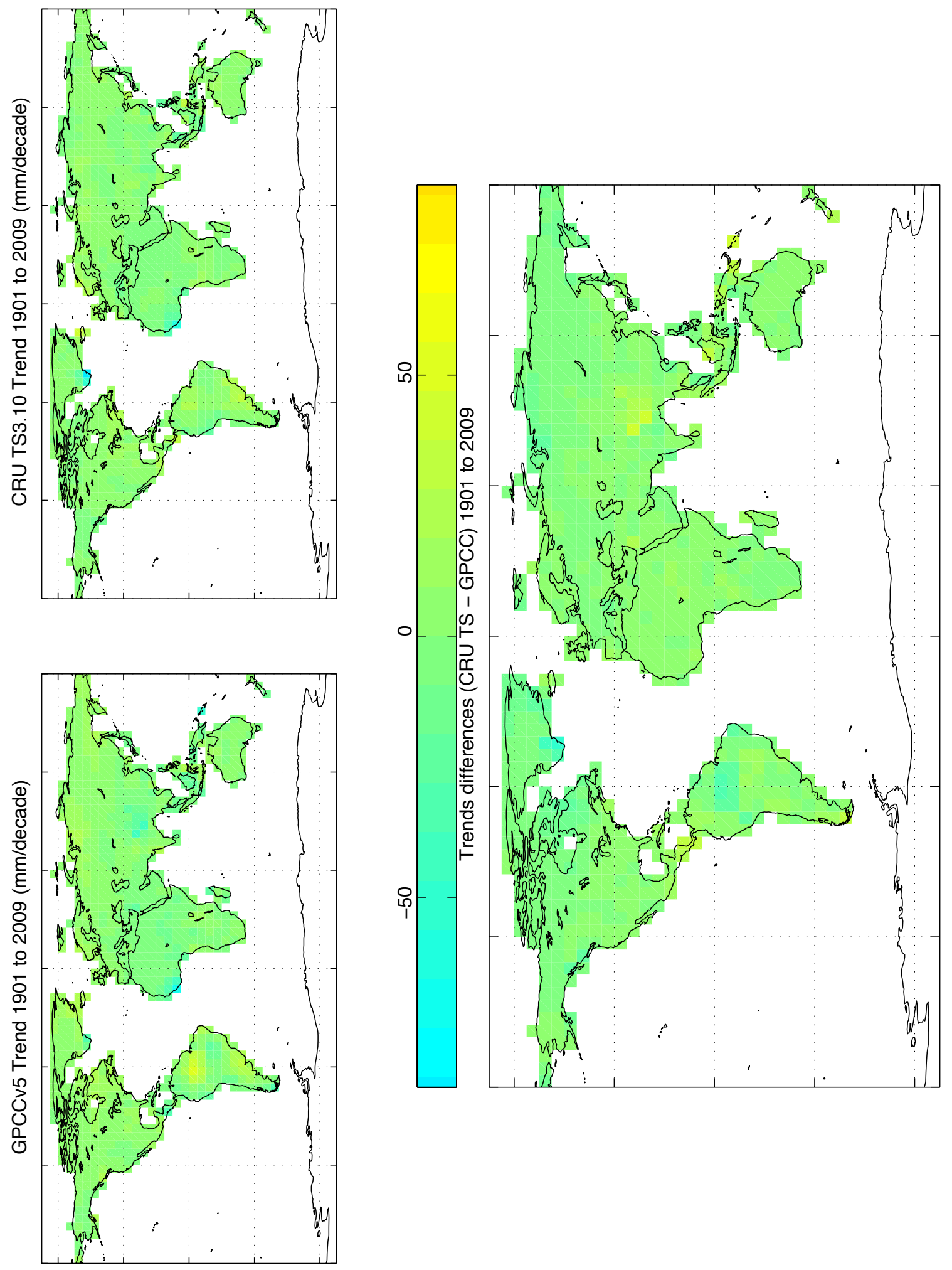

Figure S14. CRUTS and GPCCv5 trends, and their differences, for 1901 to 2009. 


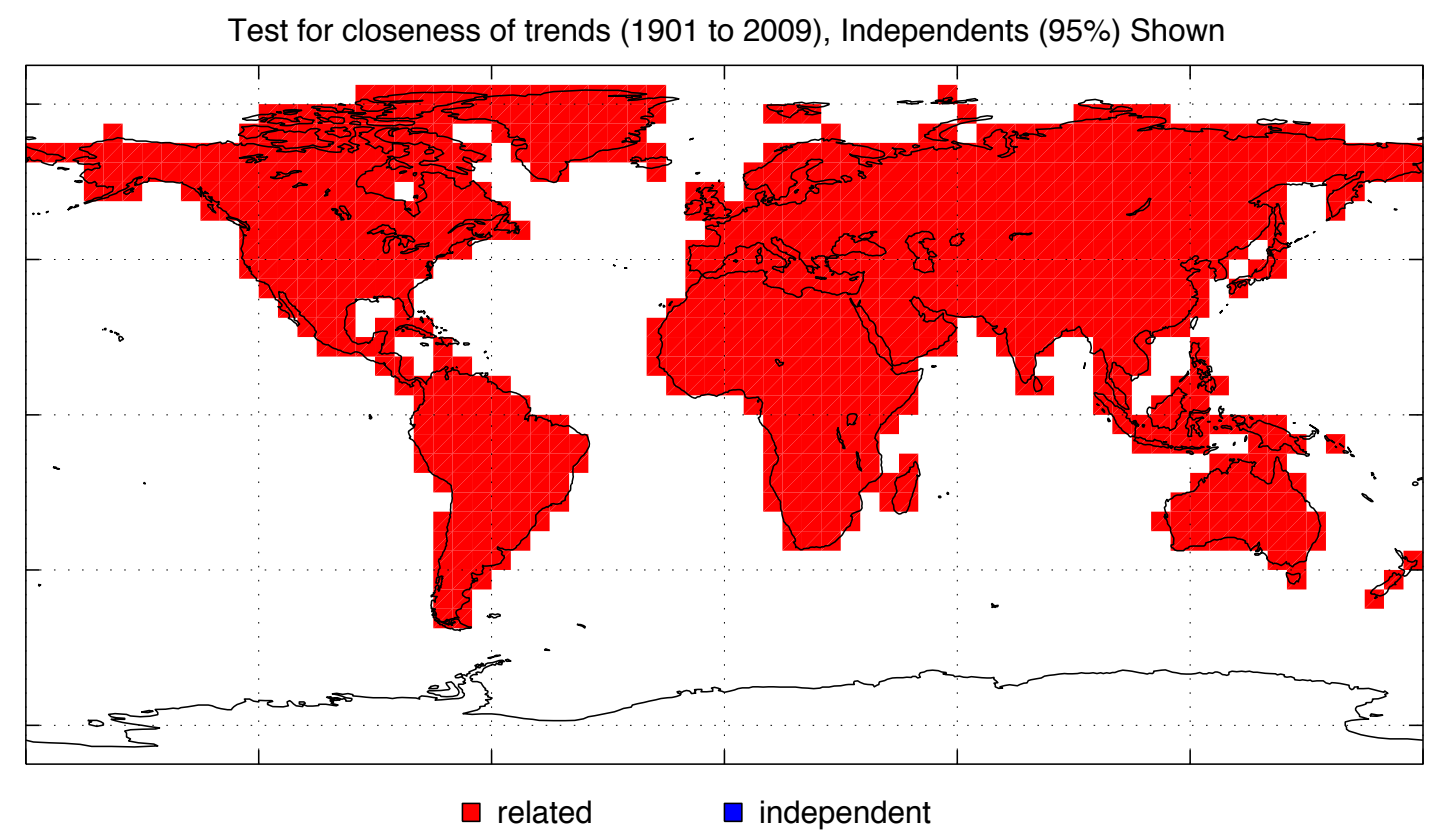

Figure S15. Locations where the CRUTS and GPCCv5 trends are consistent or are significantly different, for 1901 to 2009. 